\title{
Does Cervical Conization Represent A Realistic Treatment Option, In Young Patients with Early-Stage Cervical Cancer?
}

\author{
Georgios Androutsopoulos*, Georgios Michail, Panagiotis Panas and Georgios Adonakis \\ Department of Obstetrics and Gynaecology, University of Patras, Greece
}

Submission: December 03, 2018 ; Published: December 13, 2018

*Corresponding author: Georgios Androutsopoulos, Department of Obstetrics and Gynaecology, University of Patras, Medical School, Greece

\section{Editorial}

Cervical cancer (CC) is the most common cancer of the female reproductive system and represents a significant health problem worldwide [1,2]. The disease usually affects young patients, sometimes before completion of childbearing. In this case, the type of therapeutic approach should be carefully individualized according to disease stage, histologic subtype, fertility issues and performance status [3-9].

Especially in young patients with FIGO stage IA1 or IA2 CC and strong desire for fertility preservation, cervical conization remains a realistic treatment option $[3-5,9,10]$ Moreover, there is some evidence that selected patients with FIGO stage IB1 CC and small volume disease (less than $500 \mathrm{~mm} 3$ ) could be treated with cervical conization and pelvic lymph node dissection $[9,11,12]$.

Eligible patients shouldn't harbor any metastasis to the pelvic or para-aortic lymph nodes $[3,4,6,9]$. Moreover, they should have a thorough preoperative assessment and an extensive counseling regarding disease recurrence, oncologic outcome, fertility and pregnancy issues $[3,4,6-9,13,14]$. Especially patients with FIGO stage IB1 and small volume disease should have examination under anesthesia as well as investigation with cystoscopy and pelvic Magnetic Resonance Imaging (MRI), in order to assess the size and extent of disease $[9,11,12]$.

However, the option of conservative approach should not be offered in patients with aggressive (small cell neuroendocrine carcinoma) or potentially aggressive (gastric type adenocarcinoma, minimal deviation adenocarcinoma) histologic subtypes of CC, even at early-stage disease $[3,4,9,15,16]$.

During cervical conization, the ectocervix and endocervical canal should be excised enbloc in a single specimen $[3,8,9,17,18]$. The procedure could be performed either with cold knife, laser or electrosurgery $[3,4,8,9,17,18]$. Cold knife conization provides specimen without any thermal effect on it, which is of utmost importance in the accurate evaluation of resection margins $[3,8,9,19,20]$. Loop electrosurgical excision procedure (LEEP) should be performed with additional care, in order to minimize thermal effect on the provided specimen $[3,9,19,21]$. Especially in patients with FIGO stage IA2 with lymphovascular space invasion (LVSI) or IB1 and small volume disease, pelvic lymphadenectomy with or without sentinel lymph node (SLN) mapping should be performed, as there is increased risk of lymphatic metastasis and disease recurrence $[3,4,6,7,9-12,17,22]$. The excised lymph nodes should be evaluated using ultrastaging approach $[4,9]$. The provided surgical specimen should be examined in detail with multiple frozen sections and resection margins should be at least $3 \mathrm{~mm}$ clear for pre-invasive or invasive disease $[3,4,9]$. In case of positive resection margins, either cervical conization should be repeated or radical trachelectomy should be performed. In case of lymph node metastasis, either radical hysterectomy or primary chemo-radiotherapy should be advocated.

Perioperative morbidity rates in young CC patients treated with cervical conization are quite acceptable, being relatively low $[9,18]$. Moreover, patients have less significant perioperative complications compared with others treated with less conservative approaches (radical trachelectomy or radical hysterectomy) $[9,23]$.

Bleeding, discharge and wound infection, are the most common early postoperative complications in patients having cervical conization $[9,18]$. Cervical stenosis and impaired cervical function are the most common late postoperative complications $[9,18,24]$.

Recurrence rates are similar and quite low, for CC patients with FIGO stage IA1 and IA2 disease treated with cervical conization $[3,25,26]$. Mortality rates in CC patients with FIGO stage IA1 disease treated with cervical conization, are approximately $0.7 \%$ in case of negative resection margins [27]. Lymph node metastasis, involved resection margins and LVSI represent high risk factors for disease recurrence in CC patients treated with cervical conization $[3,4,7,9,25,28]$. 
A series of pregnancy issues related with impaired cervical function are anticipated among patients having cervical conization with depth greater than $1 \mathrm{~mm}$, irrespective of the individual technique used $[24,29,30]$. The number of conization procedures as well as the depth and volume of conization specimen have a dismal effect on cervical function $[9,24,29,30]$.

The relative risk for premature rupture of membranes ( $<37$ weeks) is significantly higher in the subgroup of patients treated with cold knife conization compared with the subgroup of others treated with LEEP, at about 4.11 (95\% CI 2.05 to 8.25) and 2.15 (95\% CI 1.48 to 3.12) respectively [29]. Moreover, the relative risk for preterm labor ( $<37$ weeks) in the subgroup of CC patients treated with cold knife conization is approximately 2.70 (95\% CI 2.14 to 3.40), while in the subgroups of patients treated with laser conization or LEEP is about 2.11 (95\% CI 1.26 to 3.54) and 1.56 (95\% CI 1.36 to 1.79 ) respectively. It is obvious that laser conization and LEEP procedure provide better pregnancy outcomes compared with cold knife conization $[9,24,30]$.

\section{Conclusion}

Cervical conization represents an acceptable treatment approach for carefully selected young patients with FIGO stage IA1 or IA2 CC and strong desire for fertility preservation, without any compromise in oncologic outcome $[3-5,9,10]$. However, all patients should have a thorough preoperative assessment and a very detailed counseling regarding disease recurrence, oncologic outcome, fertility issues and possible pregnancy complications related with impaired cervical function $[3,4,6-9,13,14]$.

\section{References}

1. WHO (2012) Estimated cancer incidence, mortality and prevalence worldwide in 2012. Globocan, France.

2. Ferlay J, Soerjomataram I, Dikshit R, Eser S, Mathers C, et al. (2015) Cancer incidence and mortality worldwide: sources, methods and major patterns in GLOBOCAN 2012. Int J Cancer 136(5): E359-E386.

3. NCCN (2018) Clinical Practice Guidelines in Oncology: Cervical Cancer. NCCNorg 16(11): 1-84.

4. Cibula D, Potter R, Planchamp F, Avall-Lundqvist E, Fischerova D, et al (2018) The European Society of Gynaecological Oncology/European Society for Radiotherapy and Oncology/European Society of Pathology Guidelines for the management of patients with cervical cancer. Int $J$ Gynecol Cancer 28(4): 641-655.

5. Marth C, Landoni F, Mahner S, McCormack M, Gonzalez-Martin A, et al. (2017) Cervical cancer: ESMO Clinical Practice Guidelines for diagnosis, treatment and follow-up. Ann Oncol 28(Suppl 4): iv72-iv83.

6. Chuang L, Temin S, Berek J (2016) Management and care of women with invasive cervical cancer: American Society of Clinical Oncology Resource-Stratified Clinical Practice Guideline. J Oncol Pract 12(7): 693-696.

7. Androutsopoulos G, Kotsopoulos I, Michail G, Decavalas G (2017) Fertility sparing approach in young patients with early stage cervical cancer. Obstet Gynecol Int J 6(2): 00197.

8. Androutsopoulos G, Kotsopoulos I, Korompelis P, Decavalas G (2017) Does conservative surgical management of early stage cervical cancer represent a persistent dilemma in young patients? OA J Surg 3(3): 555611.
9. Androutsopoulos G, Naik R (2019) Standard and novel surgical treatment in cervical cancer. In: Farghaly S (ed.), Uterine cervical cancer: clinical and therapeutic perspectives.

10. Bhatla N, Aoki D, Sharma D, Sankaranarayanan R (2018) Cancer of the cervix uteri. Int J Gynaecol Obstet 143(Suppl 2): 22-36.

11. Naik R, Cross P, Nayar A, Mayadevi S, Lopes A, et al. (2007) Conservative surgical management of small-volume stage IB1 cervical cancer. BJOG 114(8): 958-963.

12. Biliatis I, Kucukmetin A, Patel A, Ratnavelu N, Cross P, et al. (2012) Small volume stage 1B1 cervical cancer: Is radical surgery still necessary? Gynecol Oncol 126(1): 73-77.

13. Ramirez P, Pareja R, Rendon G, Millan C, Frumovitz M, et al. (2014) Management of low-risk early-stage cervical cancer: should conization, simple trachelectomy, or simple hysterectomy replace radical surgery as the new standard of care? Gynecol Oncol 132(1): 254-259.

14. Bentivegna E, Gouy S, Maulard A, Chargari C, Leary A, et al. (2016) Oncological outcomes after fertility-sparing surgery for cervical cancer: a systematic review. Lancet Oncol 17(6): e240-e253.

15. Viswanathan A, Deavers M, Jhingran A, Ramirez PT, Levenback C, et al. (2004) Small cell neuroendocrine carcinoma of the cervix: outcome and patterns of recurrence. Gynecol Oncol 93(1): 27-33.

16. Young R, Clement P (2002) Endocervical adenocarcinoma and its variants: their morphology and differential diagnosis. Histopathology 41(3): 185-207.

17. Priore DG (2011) Cone biopsy. An atlas of gynecologic oncology: CRC Press, USA, pp. 68-70.

18. Lopes T, Spirtos N, Naik R, Monaghan JM (2010) Operations on the cervix. Bonney's gynaecological surgery: Wiley-Blackwell, pp. 81-98.

19. Miroshnichenko G, Parva M, Holtz D, Klemens JA, Dunton CJ, et al. (2009) Interpretability of excisional biopsies of the cervix: cone biopsy and loop excision. J Low Genit Tract Dis 13(1): 10-12.

20. Fanning J, Padratzik J (2002) Cold knife conization vs. LEEP. Are they the same procedure? J Reprod Med 47(1): 33-35.

21. Kim M, Kim M, Kim J, Chung HH, Park NH, et al. (2012) Loop electrosurgical excision procedure findings for identification of patients with early-stage cervical cancer suitable for less radical surgery. Int J Gynecol Cancer 22(7): 1214-1219.

22. Andikyan V, Khoury-Collado F, Denesopolis J, Park KJ, Hussein y, et al. (2014) Cervical conization and sentinel lymph node mapping in the treatment of stage I cervical cancer: is less enough? Int J Gynecol Cancer 24(1): 113-117.

23. Alexander-Sefre F, Chee N, Spencer C, Menon U, Shepherd JH, et al. (2006) Surgical morbidity associated with radical trachelectomy and radical hysterectomy. Gynecol Oncol 101(3): 450-454.

24. Kyrgiou M, Koliopoulos G, Martin-Hirsch P, Arbyn M, Prendiville W, et al. (2006) Obstetric outcomes after conservative treatment for intraepithelial or early invasive cervical lesions: systematic review and meta-analysis. Lancet 367(9509): 489-498.

25. Wright J, NathavithArana R, Lewin S, Sun X, Deutsch I, et al. (2010) Fertility-conserving surgery for young women with stage IA1 cervical cancer: safety and access. Obstet Gynecol 115(3): 585-590.

26. Ditto A, Martinelli F, Bogani G, Fischetti M, Donato DV, et al. (2015) Fertility-sparing surgery in early-stage cervical cancer patients: oncologic and reproductive outcomes. Int J Gynecol Cancer 25(3): 493497.

27. Haller H, Krasevic M, Mamula O, Brnčić-Fischer A, Eminović S, et al. (2011) Treatment and outcome of stage Ia1 squamous cell carcinoma of the uterine cervix. Int J Gynaecol Obstet 113(1): 72-75. 
28. Raspagliesi F, Ditto A, Quattrone P, Solima E, Fontanelli R, et al. (2005) Prognostic factors in microinvasive cervical squamous cell cancer: long-term results. Int J Gynecol Cancer 15(1): 88-93.

29. Kyrgiou M, Athanasiou A, Paraskevaidi M (2016) Adverse obstetric outcomes after local treatment for cervical preinvasive and early invasive disease according to cone depth: systematic review and metaanalysis. BMJ 354: i3633.

30. Nam K, Kwon J, Kim Y, Park YW (2010) Pregnancy outcome after cervical conization: risk factors for preterm delivery and the efficacy of prophylactic cerclage. J Gynecol Oncol 21(4): 225-229.

Your next submission with Juniper Publishers will reach you the below assets

- Quality Editorial service

- Swift Peer Review

- Reprints availability

- E-prints Service

- Manuscript Podcast for convenient understanding

- Global attainment for your research

- Manuscript accessibility in different formats ( Pdf, E-pub, Full Text, Audio)

- Unceasing customer service

Track the below URL for one-step submission https://juniperpublishers.com/online-submission.php 